\title{
Repositório biográfico: singularidades de um modelo promissor
}

\author{
Biographical repository: singularities of a promising model \\ Repositorio biográfico: singularidades de un modelo prometedor
}

\author{
Alex Medeiros Kornalewski Alex | alexmedeiros87@hotmail.com \\ Universidade Federal do Estado do Rio de Janeiro. Rio de Janeiro, Brasil. \\ Leandro da Conceição Borges | eandrocb@bol.com.br \\ Universidade Federal do Rio de Janeiro. Rio de Janeiro, Brasil. \\ Bruna Beltrão Belinato | belinatobruna@gmail.com \\ Universidade Federal do Estado do Rio de Janeiro. Rio de Janeiro, Brasil.
}

\section{Resumo}

A Sociedade da Informação possibilitou o surgimento de novas ferramentas digitais, no qual suas metodologias são debatidas pelos seus pares cujo objetivo é aceitação pela comunidade científica. O Movimento de Acesso Aberto chancelou ao mundo dois dos seus principais pilares: os repositórios digitais (institucionais e temáticos) e os periódicos científicos. A presente comunicação se preocupa em discutir sobre o que se entende por "repositório biográfico", inquietação que se originou a partir de um grupo de estudos oriundo do curso de Especialização em Informação Científica e Tecnológica em Saúde, do Instituto de Comunicação e Informação Científica e Tecnológica em Saúde, da Fundação Oswaldo Cruz no Rio de Janeiro. O procedimento metodológico aplica uma reflexão diante da literatura disponível sobre repositório, em relação aos preceitos estabelecidos pela memória. O trabalho pretende discorrer sobre as diferenças entre os repositórios institucionais e temáticos de forma a evidenciar as singularidades que promovem o conceito de repositório biográfico. Para tal, apoia-se nas áreas do conhecimento que abordam em seu contexto aspectos distintos de definição de documento, mas que convergem na finalidade de preservar e perpetuar a memória. Portanto, um repositório biográfico para ser conhecido como tal aplica elementos da Arquivologia, Biblioteconomia e Museologia, ainda que, as suas diferenças sejam evidentes.

Palavras-chave: Repositório biográfico; Acesso aberto; Memória; Informação. 


\section{Abstract}

The Information Society enabled the emergence of new digital tools, in which their methodologies are debated by their peers whose goal is acceptance by the scientific community. The Open Access Movement has channeled to the world two of its main pillars: digital repositories (institutional and disciplinary) and scientific journals. This communication is concerned with discussing what is meant by "biographical repository", a concern that originated from a study group coming from the Specialization Course in Scientifical and Technological Information in Health, from Institute of Scientific and Technological Communication and Information in Health made of Oswaldo Cruz Foundation in Rio de Janeiro. The methodological procedure applies a reflection to the available literature on repository, in relation to the precepts established by memory. The paper aims to discuss the differences between institutional and disciplinary repositories in order to highlight the sing ularities that promote the concept of biographical repository. To this end, it relies on the areas of knowledge that approach in its context distinct aspects of document definition, but which converge on the purpose of preserving and perpetuating memory. Therefore, a biographical repository, to be known as such, applies elements of Archivology, Library Science and Museology, although their differences are evident.

Keywords: Biographical repository; Open access; Memory; Information.

\section{Resumen}

La Sociedad de la Información posibilitó el surgimiento de nuevas herramientas digitales, en el cual sus metodologías son debatidas por sus pares cuyo objetivo es la aceptación por la comunidad científica. El Movimiento de Acceso Abierto ha canalizado al mundo dos de sus principales pilares: los repositorios digitales (institucionales y temáticos) y los periódicos científicos. La presente comunicación se preocupa en discutir sobre lo que se entiende por "repositorio biográfico", inquieto que se originó a partir de un grupo de estudios oriundo del curso de Especialização em Informação Científica e Tecnológica em Saúde, del Instituto de Comunicação e Informação Científica y De la Fundação Oswaldo Cruz en Río de Janeiro. El procedimiento metodologico aplica una reflexión ante la literatura disponible sobre repositorio, en relación a los preceptos establecidos por la memoria. El trabajo pretende discurrir sobre las diferencias entre los repositorios institucionales y temáticos para evidenciar las singularidades que promueven el concepto de repositorio biográfico. Para ello, se apoya en las áreas del conocimiento que abordan en su contexto aspectos distintos de definición de documento, pero que convergen en la finalidad de preservar y perpetuar la memoria. Por lo tanto, un repositorio biográfico para ser conocido como tal aplica elementos de la Archivología, Biblioteconomía y de Museología, aunque, sus diferencias sean evidentes.

Palabras clave: Repositorio biográfico; Acceso abierto; Memoria; Información.

\section{Introdução}

$\mathrm{O}$ avanço tecnológico possibilitou o florescimento de novas metodologias pelo mundo, o que viabilizou a participação ativa das pessoas, tornando-as mais que receptoras de informação, mas também produtoras e disseminadoras de informação. Blattmann e Silva ${ }^{1}$ corroboram a afirmativa ao ressaltar que "a evolução da $W E B$ possibilita a criação de espaços cada vez mais interativos, nos quais os usuários possam modificar conteúdos e criar novos ambientes hipertextuais”. Diante desta nova ordem, eis que surge o modelo Open Archives (Arquivos Abertos) proporcionando um novo contexto mundial para a comunicação científica.

Essa proposta se iniciou na década de 90 a partir das experiências realizadas com a implantação do ArXiv, em 1991, um repositório temático na área de Ciência da Computação, Física e Matemática do Laboratório Nacional de Los Alamos, ligado à Universidade da Califórnia, no Novo México, Estados Unidos². O ArXiv foi o primeiro repositório digital do mundo cujo um dos princípios do seu surgimento foi a aderência ao movimento que começava a ser desenhado, inicialmente nos Estados Unidos, de contestação aos altos 
preços cobrados pelas assinaturas das publicações científicas fornecidas pelas grandes editoras e também na demora da publicação dos artigos alocados nesses periódicos.

O Movimento de Acesso Aberto surge como uma alternativa às regras estipuladas pelas grandes editoras científicas, que possuem um grande poderio econômico por meio de seus periódicos e bases de dados. Com o crescimento desse Movimento, ficaram definidas na declaração de Budapeste (2002) as duas principais vias do Acesso Aberto: a verde e a dourada. A via verde é voltada para o autoarquivamento, ou seja, tem por prioridade a construção de políticas que viabilizem o armazenamento, organização e disseminação da publicação científica por intermédio de repositórios digitais (institucionais ou temáticos); enquanto que a via dourada remete ao uso editorial de periódicos. Alves $^{3}$ aponta as vias como duas estratégias:

[...] a primeira é a de autoarquivamento - via verde (green road), que trata do arquivamento que poderá ser realizado pelos próprios autores de artigos científicos já publicados ou aceitos para publicação, obtendo autorização (sinal verde) dos editores que os aceitaram para que possam disponibilizar em um servidor de arquivo aberto. A segunda estratégia trata de via dourada (golden road), que abrange os periódicos científicos eletrônicos cujo acesso aberto a seus conteúdos é garantido pelos próprios editores.

Os repositórios digitais, no âmbito institucional segundo Marcondes e Sayão4, constituem-se como "[...] uma biblioteca digital destinada a guardar, preservar e garantir livre acesso, via internet, à produção científica no âmbito de uma dada instituição”. Já os repositórios temáticos, se preocupam em armazenar documentos e promover a disseminação de informação com uma delimitação concisa de sua cobertura designada por um assunto, área do conhecimento ou temática específica ${ }^{5-6}$. Dentro dessas duas esferas surgiu uma inquietação: como definir um local para a reunião da produção de um pesquisador que apresentou relevância científica? Ainda assim, além de apontar as diferenças do que verificamos ser um repositório biográfico, em comparação com as tipologias de repositórios apresentadas, também seria necessário pensar nas similaridades com as disciplinas do conhecimento que tem a memória e o documento como égide de seus trabalhos. A Arquivologia, Museologia e a Biblioteconomia, são áreas que apresentam fortes relações com o documento e a memória ainda que as finalidades formais e cotidianas sejam distintas.

Essa discussão nasceu em um grupo de estudo durante o curso de Especialização em Informação Científica e Tecnológica em Saúde, do Instituto de Comunicação e Informação Científica e Tecnológica em Saúde, da Fundação Oswaldo Cruz (Fiocruz), no Rio de Janeiro. Em linhas gerais, um repositório biográfico difere do institucional e do temático pelo propósito de salvaguardar toda a produção (científica, acadêmica ou pessoal) de um pesquisador, o que nos permite traçar uma linha de atuação desse profissional através do tempo. O institucional, conforme já demonstrado, está voltado para a reunião da produção que visa contar a história de uma instituição por meio da publicação que envolve os seus funcionários; e o temático busca a defesa de uma área do conhecimento por meio de sua produção.

Mediante ao ensejo, por se tratar de uma discussão inicial da temática, além da diferença substancial do repositório institucional e temático, torna-se necessário explicar que a reflexão sobre o repositório biográfico também não é um museu virtual ou arquivo pessoal, porém, a sua estrutura teórica-metodológica-conceitual ancora nos preceitos alicerçados nas áreas de Arquivologia e Museologia, além da Biblioteconomia, principalmente no que diz respeito à forma de como a informação é armazenada no ciberespaço ${ }^{i}$ de como a visualização da informação é tratada.

i Para Lévy (2000, p. 92-93) ciberespaço é: "[...] o espaço de comunicação aberto pela interconexão mundial dos computadores e das memórias dos computadores. Essa definição inclui o conjunto dos sistemas de comunicação eletrônicos (aí incluídos os conjuntos de redes hertzianas e telefônicas clássicas), na medida em que transmitem informações provenientes de fontes digitais ou destinadas à digitalização". 
O estudo se divide nas seguintes seções: apresentação da ciência, no contexto central da importância dos periódicos científicos de Acesso Aberto e os repositórios digitais para o fortalecimento do movimento, além de refletir sob o viés etimológico na qual as áreas do conhecimento (Arquivologia, Biblioteconomia, Museologia) e as suas diferentes concepções de documento mostram-se cruciais para promovermos um espaço de fundamentação do repositório biográfico. Em seguida, estabelecemos a defesa do repositório biográfico por intermédio da discussão conceitual inerente aos aspectos da memória. A funcionalidade de um repositório biográfico relacionando-o com a dúplice memória e informação se fazem presentes. Por fim, são apresentadas as considerações, e principalmente as inquietações dedicadas ao porvir.

\section{Biblioteca, arquivo e museu: semelhanças e singularidades quanto ao tratamento documental}

O processo da comunicação científica foi moldado e estruturado com o tempo. Com a criação e o fomento de diversos veículos comunicacionais o periódico científico, a partir do século XVII até os dias atuais, constitui-se como o principal mecanismo difusor da ciência fortalecendo-se por meio dos suportes de organização e transferências de informação entre os pares, e a propagação em larga escala aos experimentos de pesquisa pelos cientistas para outros pesquisadores, independente da sua localização geográfica. Contudo, o anseio e crescimento por informação científica tornou-se crescente, e novas possibilidades surgem no mundo contemporâneo fortemente apoiado pelas Tecnologias de Informação e Comunicação (TIC). O suporte tradicional de transferência da informação científica baseado no papel, poderia ser representado e difundido no universo online. O Movimento de Acesso Aberto à informação científica começa a ser desenhado em meio a esse contexto em que os aspectos sociais e econômicos impõem novas formas de se conviver.

A primeira expressão significativa do Movimento de Acesso Aberto se deu com o Arxiv, em 1991. Cientistas da Física, Matemática e áreas afins, buscando representatividade e afirmação em meio ao poderio das editoras científicas, que cobravam preços cada vez maiores para a assinatura dos títulos de periódicos comercializados o que inviabilizava a continuidade das assinaturas pelas bibliotecas norte-americanas. No Arxiv o pesquisador tinha a liberdade de publicar os seus preprints (arquivos sem a avaliação dos pares) no repositório, sem que houvesse cobrança monetária por isso. Tal prática consistia em um dos pontos centrais de críticas aos que eram contrários à aceitação da legitimidade do Movimento. A experiência do Arxiv possibilitou que outros repositórios fossem criados pelo mundo fortalecendo os laços do Movimento. Em 2002 ocorre a Reunião de Budapeste sacramentando a via verde e a via dourada. Desde então ocorrem diversas expressões pelo mundo que buscam fortalecer a aderência ao Movimento, como as Reuniões de Bedestha (2003) e Berlim (2003) assim como a Conferência Luso-brasileira de Acesso Aberto (Confoa), por exemplo.

Dentre as possibilidades de repositórios digitais comumente propagados estão o institucional e o temático cujas definições já foram explicitadas. Todavia, como pensar em uma nova nomenclatura de repositório tendo em vista o amplo reconhecimento dos dois supramencionados? Buscamos elencar algumas características, definidas na literatura científica, para entender como um repositório biográfico pode se tornar presente.

Kuramoto $^{7}$ declara que apesar da nebulosidade em definir conceitualmente o que é uma biblioteca digital, um repositório digital também pode ser considerado uma biblioteca digital em função das similaridades de ambos em armazenar objetos digitais. No entanto, infere-se que a diferença substancial entre um produto e outro estaria na finalidade e singularidade do armazenamento: um repositório institucional armazena produções para a constituição de memória de uma instituição; o repositório temático armazena produções de uma área do conhecimento e uma biblioteca digital armazena produções que estejam definidas no escopo da política de desenvolvimento de coleções. Etimologicamente, a palavra repositório deriva do latim repositorŭum, que significa local de guarda. A palavra arquivologia deriva do latim archivum, que significa arquivo e, em linhas gerais, é o lugar onde os documentos são guardados. A Museologia vem inicialmente 
do grego mouseîon e posteriormente do latim museum, cujo significado é o de templo das musas, e a sua finalidade está na preservação da memória de uma pessoa, um lugar etc, utilizando-se, em muitos casos, de artefatos imagéticos que visam contar uma história ${ }^{8}$.

Arquivo e museu, assim como as bibliotecas, foram por muito tempo locais que estavam fisicamente no mesmo ambiente, compartilhando do mesmo acervo ${ }^{8}$. A fragmentação entre os espaços surge na modernidade com a transição social, principalmente com a Revolução Francesa, e a necessidade cada vez mais presente de mão-de-obra especializada ${ }^{8}$. As áreas utilizam de documentos para as atividades práticas de sua existência, assim como um repositório digital também utiliza, tendo as diferenças presentes na finalidade de propósito do documento em cada área. Para Paul Otlet e Henri La Fontaine (tidos como os precursores da documentação), o documento apresenta caráter representativo, quando salvaguardado e mantido por arquivos, bibliotecas e museus, indo além do suporte físico, e das instituições de guarda que são responsáveis pelo processo informativo-documental de formas distintas, cada qual com a sua especificidade, como destacado por Tanus e Araújo ${ }^{8}$. Vale destacar que para os autores, a Arquivologia tem como objetivo a difusão da informação, e é "compreendida através de um sentido totalizador, onde se encontram os documentos, processos teóricos e práticos necessários para o cumprimento das funções dos arquivos”; já a Biblioteconomia, uma ciência documental que "consiste em um conjunto organizado de documentos e sistemas de informação". Entretanto, para ambas as ciências documentais, o documento só se torna um documento quando relacionado com o sujeito e o espaço. Em linhas gerais, o arquivo pode ser observado do ponto de vista público ou privado, apresentando características elementares, como: criar, avaliar, adquirir, classificar, descrever, comunicar e conservar documentos gerados a partir da prática funcional das atividades9.

Também se discute o arquivo pelo ponto de vista de seu conteúdo, no qual os aspectos da unicidade, organicidade, indivisibilidade, integridade, autenticidade e heterogeneidade se fazem presentes ${ }^{9}$. Paes ${ }^{10}$ em sua análise diferencia a Arquivologia da Biblioteconomia, no que diz respeito ao documento, sendo: a Arquivologia a área que analisa os documentos em conjuntos e a Biblioteconomia o campo de conhecimento que analisa individualmente cada elemento do documento. Já a Museologia, frente a multiplicidade de documentos à sua disposição, em diferentes suportes, tem como propósito a preservação, investigação, e a comunicação com a finalidade de disseminação do seu objeto de pesquisa.

O processo de gestão documental em um repositório biográfico permite reunir os pilares descritos em todos os exemplos demonstrados: pode conter produção científica de um autor notório durante o seu tempo de atuação em uma determinada instituição; a produção balizada em uma determinada área do conhecimento; documentos com fins arquivísticos reunidos em conjunto; objetos que buscam contar a história de vida de um determinado sujeito notório, divididos, classificados, catalogados, indexados em algum local do ciberespaço. A dimensão que a internet proporciona por meio do acesso é ampla. Podemos dizer que um repositório biográfico aproxima essas áreas, conhecidos como "as três marias", Biblioteconomia, Arquivologia e Museologia, através dos conceitos: instituição, memória, documento e informação. Como características comuns entre as áreas, observa-se em Tanus e Araújo ${ }^{8}$ que tanto bibliotecas, arquivos e museus tem a preocupação de coletar e constituir a memória, gerenciar coleções e dar acesso às mesmas.

Apesar dos muitos conceitos comuns que circundam as áreas como: a representação, disseminação, preservação, mediação, comunicação; cada qual armazena a informação conforme a utilidade que lhe foi conferida, como é salientado por $\mathrm{Smit}^{12}$, que diz que as diferenças se baseiam em dois eixos complementares que são os acervos e as instituições que abrigam esses acervos. Smit ${ }^{11}$, coloca que "em la imaginación professional colectiva, los libros y periódicos se almacenam em las bibliotecas, los objetos em los museos y los documentos que generam las administraciones em los archivos”, e assim coloca a diferença apoiada nas distinções dos suportes documentários, nas metodologias de organização que surgem a partir dessa distinção e pelo trabalho de organização da informação adequado aos objetivos institucionais, como já mencionado anteriormente. Smit ${ }^{11}$ ainda destaca a função da informação como principal diferença de bi- 
bliotecas e arquivos. Todas as ciências documentais trabalham com documentos, mas o tratamento que é dado pela Biblioteconomia em função das práticas profissionais da área, dos paradigmas existentes, da forma de gestão do armazenamento da informação alcançado pelo processamento técnico em um nível mais avançado da informação propriamente dita, analogamente, é o que lhe confere a responsabilidade da gestão de um repositório biográfico.

\section{Repositório biográfico: por uma ode à experiência humana}

Todavia, alguns apontamentos são necessários. Em primeiro lugar, devemos nos aprofundar sobre o conceito de biográfico. Em termos etimológicos, a palavra nos remete a vida (bio) + escrita (grafia), ou seja, uma vida cujo registro se dá por intermédio de meios impressos, audiovisuais e demais formatos que podem ser empregados para captar, dentro do possível, os vestígios deixados, de forma voluntária ou involuntária, de uma determinada pessoa. Logo, uma biografia pode apresentar uma miríade de experiências que se constituem e são legitimadas por suas narrativas, o que incita-nos a pensar sobre a riqueza oriunda das experiências ${ }^{13}$.

Em segundo lugar, ao utilizarmos o conceito de repositório biográfico, empregamos um método que tem por objetivo captar, guardar, preservar e garantir livre acesso sobre o conteúdo, ou experiência registrada, de uma determinada pessoa, independente do suporte. Ao mesmo tempo, o repositório citado trata da memória daquele que, ao ter seus registros de vida salvaguardados, também viabilizam o armazenamento de registros das instituições e pessoas próximas do biografado, haja vista que não há uma memória plenamente individual, mas sim uma memória coletiva, ou seja, "cada memória individual é um ponto de vista sobre a memória coletiva" ${ }^{14}$. Em suma, falar de um repositório biográfico, não significa que o mesmo será utilizado apenas para guardar toda a memória de um único sujeito, mas sim toda memória coletiva que circunda o biografado, a partir de suas publicações com demais autores, pesquisas feitas com colaboradores, referências utilizadas no decorrer do seu trajeto de vida, documentos que são construídos em variadas instituições, por exemplo, os programas de parceria institucional para pesquisas e afins.

Entretanto, algumas características - sob a ótica da memória - se apresentam quando discutirmos o conceito de repositório biográfico. Essa metodologia possui uma flexibilidade, se compararmos com os repositórios institucionais ou temáticos. No primeiro caso, temos um modelo que propicia o gerenciamento da informação de uma determinada instituição, enquanto que no segundo caso, o foco é um campo, tema ou assunto específico. No caso dos repositórios biográficos, há uma possibilidade de gerenciar documentos oriundos de diversas instituições, temáticas, ou mesmo apresentar tipologias documentais singulares, tais como: fotos pessoais, cartas, maquetes, slides de apresentações, sendo que este repositório pode assumir diferentes papéis de acordo com aquele que o gerencia e com o ambiente no qual esse modelo se relaciona ${ }^{14}$.

Para além da flexibilidade, o repositório biográfico implica em uma decisão ética e política. Todos os registros utilizados para povoar o repositório não podem ser vistos como objetos inócuos, pois surgem de uma montagem não só do biografado, mas também "da sociedade que os produziu, como também das sociedades onde continuam a viver, chegando até a nossa. Essa montagem é intencional e se destina ao porvir" ${ }^{15}$. Assim sendo, da mesma forma que o repositório institucional e o temático são construídos a partir de um jogo de forças, no qual determinadas escolhas são feitas em detrimento de outras, também temos essa luta na constituição do repositório biográfico, haja vista que há uma intencionalidade que perdura quanto ao que pode ser armazenado e, por conseguinte, disseminado. Contudo, trabalhar na construção e legitimação da memória de um sujeito por intermédio das ferramentas tecnológicas que consolidam o repositório envolve uma política singular, pois ao invés do foco ser em uma instituição, portanto uma miríade de sujeitos, ou focar em uma determinada temática, no qual também temos uma multiplicidade de atores, no caso dos repositórios biográficos temos o foco em um sujeito, cuja relação com outros atores (pessoas, instituições e campos temáticos) se estabelece a partir das formas de comunicação formal e 
informal, sempre voltadas para a pessoa cuja política do repositório promove, ou seja, a construção do repositório não ocorre por meio de uma rede difusa de personagens, mas sim por uma rede centrada em um único ponto de conexão ${ }^{16}$.

Logo, os repositórios biográficos não possuem uma função reducionista de apenas salvaguardar a memória de uma determinada pessoa e suas relações, pois já nascem com o objetivo de promover uma ação futura, dito de outra forma, "reter o que já não é, antecipar o que ainda não é", tal como Bergson ${ }^{17}$ afirma. Aliais, a partir da lógica de salvaguardar, é comum vermos o equívoco discursivo no uso do termo "resgate". Os repositórios biográficos não têm o propósito de resgatar a memória de um determinado sujeito, pelo simples fato de que a construção desta metodologia de organização e disseminação de informação, permite ao mesmo tempo a construção de uma memória que se apoia no passado, mas que se constitui no presente com vistas ao vindouro, ou seja, a memória cujo repositório biográfico promove é viva, em constante ebulição e atualização, haja vista que memória não é algo a ser "resgatado" como se fosse um objeto congelado no tempo e passível de ser fisgado por um pescador muito habilidoso, cuja característica principal é a de não modificar ou deturpar esse "peixe" chamado memória.

Devemos ressaltar que o repositório biográfico não é uma verdade absoluta do sujeito cujo material que lhe faz referência está sendo alocado com o intuito de promover a disseminação da informação. Apesar de constituirmos a memória de um pesquisador, é mister o cuidado como fato de que toda memória é um processo que envolve o embate entre lembranças e esquecimentos, ou seja, a partir daí, temos a noção de que toda memória é ao mesmo tempo algo que está em evidência, mas que também deixou muitos fragmentos ancorados ao esquecimento ${ }^{18}$. Outrossim, o repositório biográfico e as demais tipologias de repositórios não podem ser vistos como um meio que promova o armazenamento total e completo de documentos sobre uma determinada instituição, campo temático ou sujeito, pois para além das questões éticas e políticas, a simples existência de um espaço de recordação, denota que o repositório é um local em que ocorre sempre a alternância de presenças e ausências, pois o ato de recordar, neste caso, promover o acesso à memória do biografado, permite que algo "desapareça temporariamente e se deposite em outro lugar, de onde se possa resgatá-la" ${ }^{19}$. Ou seja, a construção do repositório biográfico envolve uma força de recordação, no qual aqueles que povoam o sistema com documentos diversos, exerçam constantemente o trabalho de "arqueólogos", procurando em diversos arquivos, dialogando com diversas pessoas, em prol de um modelo que consiga dar conta da memória de uma pessoa, porém memória esta que nunca estará finalizada, tendo em vista que a memória é uma construção dinâmica e infindável, ao mesmo tempo que permite a construção de uma informação potencial (ainda sem valor de uso), informação consolidada, ou mesmo a informação que se transforma em conhecimento, sendo útil para tomadas de decisão ${ }^{20}$.

\section{Apontamentos sobre a tecnologia do repositório biográfico}

Se falamos de um repositório biográfico como uma metodologia singular, em comparação com o conceito de repositório institucional e repositório temático, significa dizer que, para além das questões pertinentes a memória, flexibilidade e prerrogativas ética e políticas, também é mister um espaço para discutir alguns apontamentos sob a ótica tecnológica. Neste ponto, as ferramentas disponíveis para a construção de um repositório biográfico devem dar conta dos fatores citados, de forma a promover uma comunicação eficiente entre as diversas tipologias documentais inerentes a um determinado pesquisador, ou seja, podemos pensar esta questão a partir do conceito de hipertexto, no qual a informação armazenada apresenta uma estruturação associativa, tal como a estrutura da memória o ée ${ }^{21}$.

Conforme o autor, a lógica do hipertexto complementa o que se entende por repositório biográfico, pois nos permite "substituir as estruturas clássicas arborescentes da informação por estruturas mais ricas e mais complexas, organizadas em redes, mostrando um número infinito de caminhos, abertos a todas 
as navegações e interligando múltiplos objetos”21. Contudo, uma ressalva se faz necessária: no caso dos repositórios, a questão da substituição não é revista por completo, uma vez que a organização da informação, por exemplo, por intermédio das comunidades, subcomunidades, coleções e itens (documentos), ainda podem ser aplicadas, seja por uma questão da ferramenta que será utilizada na construção do repositório biográfico (DSpace e similares), ou pelo fato de ser pertinente uma estruturação mínima dos documentos que compõem o repositório biográfico.

A ideia de povoamento de um repositório biográfico consiste em reunir em um único lugar no ciberespaço tudo o que for pertinente sobre um notável, ainda que se respeite a integralidade dos seus objetos de origem. Ao respeitar a integralidade, o repositório biográfico evita duplicatas e proporciona apenas um caminho para o documento de origem. Caso o documento não esteja disponível em nenhuma plataforma, o mesmo passa a ser disponibilizado seguindo o passo a passo de submissão comumente aplicado no povoamento de um repositório digital. A singularidade do repositório biográfico está na tentativa de disponibilizar o material de um notório e contar uma história por meio de sua produção, estabelecendo uma política documental integralista, no qual para além dos documentos in situ do repositório, também se constrói as remissivas para documentos alocados em outras bases digitais. Verifica-se que para além do software utilizado na construção do repositório biográfico, a preocupação recai na infraestrutura, especificamente no estabelecimento de conexões arborescentes entre as múltiplas tipologias documentais povoadas em plataformas distintas.

Logo, os protocolos de interoperabilidade são cruciais para construir, povoar e promover uma manutenção salutar do repositório biográfico, tais como o protocolo Z39.50 (que versa sobre a interoperabilidade dos metadados), softwares universais de leitura (que permitam a visualização de documentos nos formatos PDF, JPG, JPEG, MP3, AVI) e afins.

\section{Considerações}

A partir dos apontamentos discutidos neste trabalho, verificamos que há algumas singularidades no que diz respeito a construção de um repositório biográfico, tendo em vista que a questão da memória se apresenta de uma forma mais aprofundada para entendermos o processo de elaboração de um modelo que pretende evocar e registrar a vida de um sujeito, ao mesmo tempo em que se preocupa com a questão do Acesso Aberto a toda experiência que remete não apenas ao biografado, mas sim a suas múltiplas relações, seja institucional, pessoais e afins. Pontos como a discussão ética, política, memória, tecnologia e acesso, demonstram que o caminho é longo e árduo, porém nos convida a refletir sobre uma demanda que urge por novas soluções.

Diante das reflexões apresentadas, verificamos que um repositório temático não abarca a totalidade de obras de uma determinada pessoa, pois a mesma pode perpassar por diferentes áreas do conhecimento ao longo de sua trajetória. Além disso, alimentar um repositório temático nessas condições provocaria uma dispersão da informação, haja vista que a política para esta tipologia de repositório seria fragilizada ao apresentar uma ferramenta povoada com uma multiplicidade de documentos que, em termos de especificidade de um campo ou assunto, não atenderia os requisitos citados.

Em aditamento, o repositório institucional também não se aplica, pois a produção anterior e ou posterior ao tempo de permanência do sujeito em uma determinada instituição também seria entregue ao esquecimento, ao mesmo tempo em que promoveria a fragmentação da informação, pois as pesquisas feitas pelos viés de um sujeito biografado deveria trilhar inúmeras instituições, repositórios e afins. Logo, a ideia de um repositório biográfico, que considere as singularidades necessárias para a construção e implementação de sua política em consonância com as ferramentas de organização e disseminação de informação, podem 
ser o notável caminho a suprir essa demanda e preencher essa lacuna e necessidade de informação sobre um biografado e suas relações interpessoais e institucionais.

A dificuldade apresentada no estudo constituiu na falta de literatura sobre a temática o que apresentou maiores esforços para tentar alicerçar o conceito de repositório biográfico nos dois tipos principais (institucional e temático) e as contribuições da Biblioteconomia, Arquivologia e Museologia, destacando as suas similaridades e diferenças. As discussões sobre a estrutura política e tecnológica também foram postas em evidência para justificar a existência de um repositório biográfico. Todavia, a proposta foi a de se levantar uma discussão quanto à necessidade de prover acesso a documentos que narram à memória de um sujeito em especifico, o que implica em um caminho longo e árduo, porém necessário, no que diz respeito ao acesso aberto desta tipologia singular de repositório.

\section{Referências}

1. BLATTMANN U; Da SILVA FCC. Colaboração e interação na web 2.0 e biblioteca 2.0. Revista ABC: Biblioteconomia em Santa Catarina [Internet]. 2007 [citado em 22 abr. 2017]; 12(2): 191-215. Disponível em: https://revista.acbsc.org.br/racb/article/view/530/664.

2. KURAMOTO H. Informação científica: proposta de um novo modelo para o Brasil. Ciência da Informação [Internet]. 2006 [citado em 21 abr. 2017]; 35(2); Disponível em: http://www.scielo.br/pdf/ci/v35n2/ a10v35n2.pdf.

3. ALVES VBA. Open Archives: via verde ou via dourada? Ponto de Acesso [Internet]. 2008 [citado em 22 abr. 2017]; 2(2): 127-137. Disponível em: https://portalseer.ufba.br/index.php/revistaici/article/ view/1780/2172.

4. MARCONDES CH, SAYÃO LF. Introdução: repositórios institucionais e livre acesso. In: SAYÃO LF, TOUTAIN LB, ROSA FG, MARCONDES CH (Org.). Implantação e gestão de repositórios institucionais: políticas, memória, livre acesso e preservação. Bahia: EDUFBA; 2209.

5. MONTEIRO F, BRÄSCHER M. Organização da informação em repositórios temáticos: o uso da modelagem conceitual. In: Anais do 8. Encontro Nacional de Pesquisa em Ciência da Informação; 2007 out. 28-31; Salvador, Bahia. Salvador: ENANCIB; 2007. [citado em 18 set. 2017]; p. 1-12. Disponível em: http://www.enancib.ppgci.ufba.br/artigos/GT2--261.pdf.

6. GUIMARÃES MCS, SILVA CH, NORONHA IH. Los repositórios temáticos en la estratégia de la iniciativa Open Access. Nutr. Hosp [Internet]. 2012 [citado em 18 set. 2017]; 27 (supl. 2): 34-40. Disponível em: http://scielo.isciii.es/pdf/nh/v27s2/05articulo05.pdf.

7. KURAMOTO H. Distinguindo os conceitos de repositórios e publicações eletrônicas. Blog do Kuramoto [Internet]; 2008 [citado em 18 set. 2017]. Disponível em: https://kuramoto.wordpress.com/2008/12/08/ distinguindo-os-conceitos-de-repositorios-e-publicacoes-eletronicas/.

8. TANUS GFSC, ARAÚJO CAA. Proximidades conceituais entre Arquivologia, Biblioteconomia, Museologia e Ciência da Informação. Biblionline. 2012 [citado em 18 set. 2017]; 8(2): 27-36. Disponível em: http:// periodicos.ufpb.br/index.php/biblio/article/viewFile/14291/8635.

9. ROUSSEAU J-Y; COUTURE C. Os fundamentos da disciplina arquivística. Lisboa: Dom Quixote; 1998.

10. BELLOTTO HL. Arquivos permanentes: tratamento documental. 4 ed. Rio de Janeiro: FGV; 2006.

11. PAES ML. Arquivo: teoria e prática. Rio de Janeiro: FGV; 2006.

12. SMIT J. Archivología, Biblioteconomía y Museología. Semejanzas y diferencias. Ciencias de la Información. Cuba, 30(3): 3-10, set. 1999.

13. BENJAMIN W. Experiência e pobreza. In: ___. Magia e técnica, arte e política: ensaios sobre Literatura e História da Cultura. São Paulo: Brasiliense; 2012. v. 1.

14. HALBWACHS M. A memória coletiva. 2 ed. São Paulo: Centauro; 2006.

15. GONDAR J. Quatro proposições sobre memória social? In: GONDAR J, DODEBEI V (Org.). O que é memória social? Rio de Janeiro: Contra Capa; 2005. 
16. MARTELETO RM. Análise de redes sociais: aplicação nos estudos de transferência da informação. Ci. Inf. [Internet]. 2001 jan./abr. [citado em 16 set. 2017]; 30(1): 71-81. Disponível em: http://www.scielo.br/ pdf/ci/v30n1/a09v30n1.pdf.

17. BERGSON H. A energia espiritual. São Paulo: WMF Martins Fontes; 2009.

18. POLLACK M. Memória, esquecimento e silêncio. Estudos Históricos [Internet], 1989. [citado em 19 set. 2017]; 2(3): 3-15. Disponível em: http://www.uel.br/cch/cdph/arqtxt/Memoria esquecimento silencio. pdf.

19. ASSMANN A. Espaços da recordação: formas e transformações da memória cultural. Campinas, SP: Unicamp; 2011.

20. VARELA A. Informação e construção da cidadania. Brasília: Thesaurus; 2007

21. COADIC Y-F. A ciência da informação. 2 ed. Brasília, DF: Briquet de Lemos; 2004. 